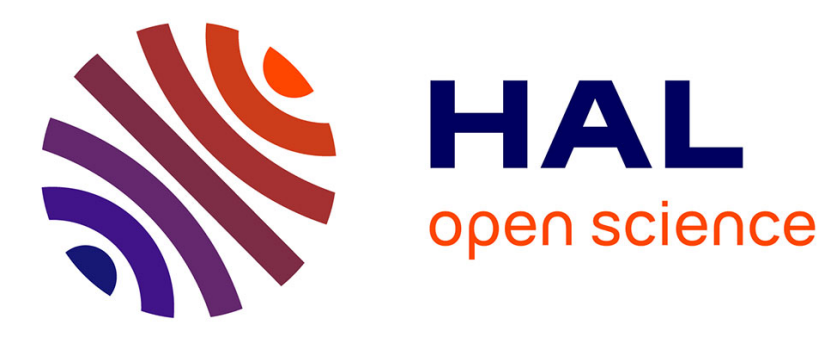

\title{
Amphiphilic photo-induced triblock polyoxazoline through coumarin dimerization: Efficient synthetic tool for nanoparticles
}

Laetitia Korchia, Cécile Bouilhac, Jean-Jacques Robin, Vincent Lapinte

\section{To cite this version:}

Laetitia Korchia, Cécile Bouilhac, Jean-Jacques Robin, Vincent Lapinte. Amphiphilic photo-induced triblock polyoxazoline through coumarin dimerization: Efficient synthetic tool for nanoparticles. European Polymer Journal, 2017, 88, pp.636-644. 10.1016/j.eurpolymj.2016.09.024 . hal-01487016

\author{
HAL Id: hal-01487016 \\ https://hal.science/hal-01487016
}

Submitted on 4 Sep 2017

HAL is a multi-disciplinary open access archive for the deposit and dissemination of scientific research documents, whether they are published or not. The documents may come from teaching and research institutions in France or abroad, or from public or private research centers.
L'archive ouverte pluridisciplinaire HAL, est destinée au dépôt et à la diffusion de documents scientifiques de niveau recherche, publiés ou non, émanant des établissements d'enseignement et de recherche français ou étrangers, des laboratoires publics ou privés. 


\title{
Amphiphilic Photo-Induced TriblockPolyoxazoline Through Coumarin Dimerization: Efficient Synthetic Tool for Nanoparticles
}

\author{
LaetitiaKorchia, ${ }^{\mathrm{a} C e ́ c i l e B o u i l h a c},{ }^{\mathrm{a}}$ Jean-Jacques Robin, ${ }^{\mathrm{a}}$ Vincent Lapinte ${ }^{\mathrm{a} *}$
}

${ }^{a}$ Institut Charles Gerhardt Montpellier UMR5253 CNRS-UM-ENSCM, Equipe Ingénierie et Architectures Macromoléculaires

\begin{abstract}
Amphiphilic photo-induced triblock copolymers were successfully prepared by photodimerization of a photo-active initiator bearing coumarin moieties $\left(\mathrm{CmTs}_{2}\right)$ before synthesizing, by cationic ring-opening polymerization (CROP), various lengths of polyoxazoline block. The DLS and TEM studies of the triblockcopolymers self-assembly in water revealed that over $99 \%$ of the nanoparticles have a $\mathrm{D}_{\mathrm{H}^{-}}$value of $10 \mathrm{~nm}$. The total photoactivity of the coumarin units permitted $\pi$-stacking interactions in the nanoparticle core and further its crystallization as demonstrated by DSC and X-ray diffractometry. An original nonspherical morphology of the nanoparticles resulted with an elongated shape.
\end{abstract}




\section{Introduction}

Amphiphilic copolymers are particularly interesting for their ability to self-assemble in selective solvents. ${ }^{[1-6]}$ The stability of polymeric micellar systems is a crucial condition for some applications such as the encapsulation of active compounds. ${ }^{[7,8]}$ Various approaches have been proposed to stabilize polymeric micelles. Among them, the core-crosslinkedmicelle and the shell-crosslinked micelle are attractive ways to maintain the structural integrity of micellar object whatever the external conditions such as the dilution or thermal changes. ${ }^{[9-}$ ${ }^{17]}$ To prepare core-crosslinked polymeric micelles, numerous approaches have already been described including free-radical reaction, condensation, ${ }^{[10,18]}$ sol-gel or click chemistry. ${ }^{[19,}$ ${ }^{20]}$ Nevertheless, these routes require some additives or initiators and produce by-products. ${ }^{[21-}$ ${ }^{23]}$ An attractive alternative is the photo-crosslinking: rapid, efficient, non-toxic and costeffective process. ${ }^{[24-29]}$ Among the current photo-crosslinkers employed (cinnamate, ${ }^{[30]}$ thymine ${ }^{[31]}$ benzophenone ${ }^{[32]}$ or anthracene ${ }^{[33]}$ ), we focus on the coumarin analoguesinter alia used in medicine, biology, and material science. ${ }^{[22,34]}$ Coumarinphotodimerizes into cyclobutane ring via a $[2 \pi+2 \pi]$ cycloaddition under UV-irradiation at $\lambda>310$ $\mathrm{nm}$, and the resulting dimer can be reversibly dissociated into the two precursor unimers at $\lambda<$ $260 \mathrm{~nm} \cdot{ }^{[8,34-38]}$ Recently, the reversible photo-dimerization of coumarin has been explored for

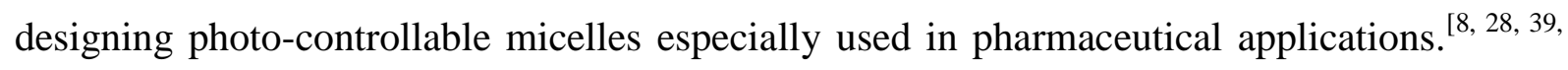
${ }^{40]}$ For example, Luoand al.prepared photo-crosslinkeddendrimericmicelles containing stable coumarin units under physiological media. ${ }^{[41]}$ Otherwise, Jiet al. described a dual photo- and pH-responsive polymers bearing coumarin units avoiding unfavorable premature release of loaded drugs. ${ }^{[42]}$

Furthermore, polyoxazolines (POx)s represent valuable bioinspiredpolymers considered as an alternative to PEG. The pseudo-peptidicstructure leads to biocompatibility, biodistribution, 
blood clearance and proteinadsorption properties. ${ }^{[43,44]}$ Well-defined POx are easily prepared by cationic ring-opening polymerization (CROP) of the corresponding 2-R-2-oxazolines. The properties of the POx depend on the nature of the $\mathrm{R}$ pendant chain (Me, Et, Pr, etc.). Manymacromolecular architectures have already beendescribed using hydrophilic and/or hydrophobic 2-oxazoline monomers or coupled to other polymer blocks. ${ }^{[45]}$ The POx could be also combined to other polymerization processes. ${ }^{[46]}$ All these strategies explained the keen interest of the manifold investigations on the decoration of POxusing functional terminating agents ${ }^{[47]}$ or initiators. ${ }^{[48-58]}$ Recently, we described the synthesis of amphiphilicdiblockpolyoxazolines $\left(\mathrm{Cm}-\mathrm{POx}_{\mathrm{n}}\right)$ bearing an UV-sensitive coumarin end-group (Figure 1, top route) as well as their self-assembly in water into spherical nanoparticles and finally their photo-dimerization. ${ }^{[59]}$

In this contribution, we report on an alternative pathway where the dimerization of the coumarin moieties is performed prior to the polymerization of 2-methyl-2-oxazoline and finally the self-assembly in water of the resulting symmetricaltriblock copolymers (Figure 1, down route). ${ }^{[59]}$ Herein, the advantages of the triblock copolymers route onto the size and the shape of the resulting nano-objects are detailed.

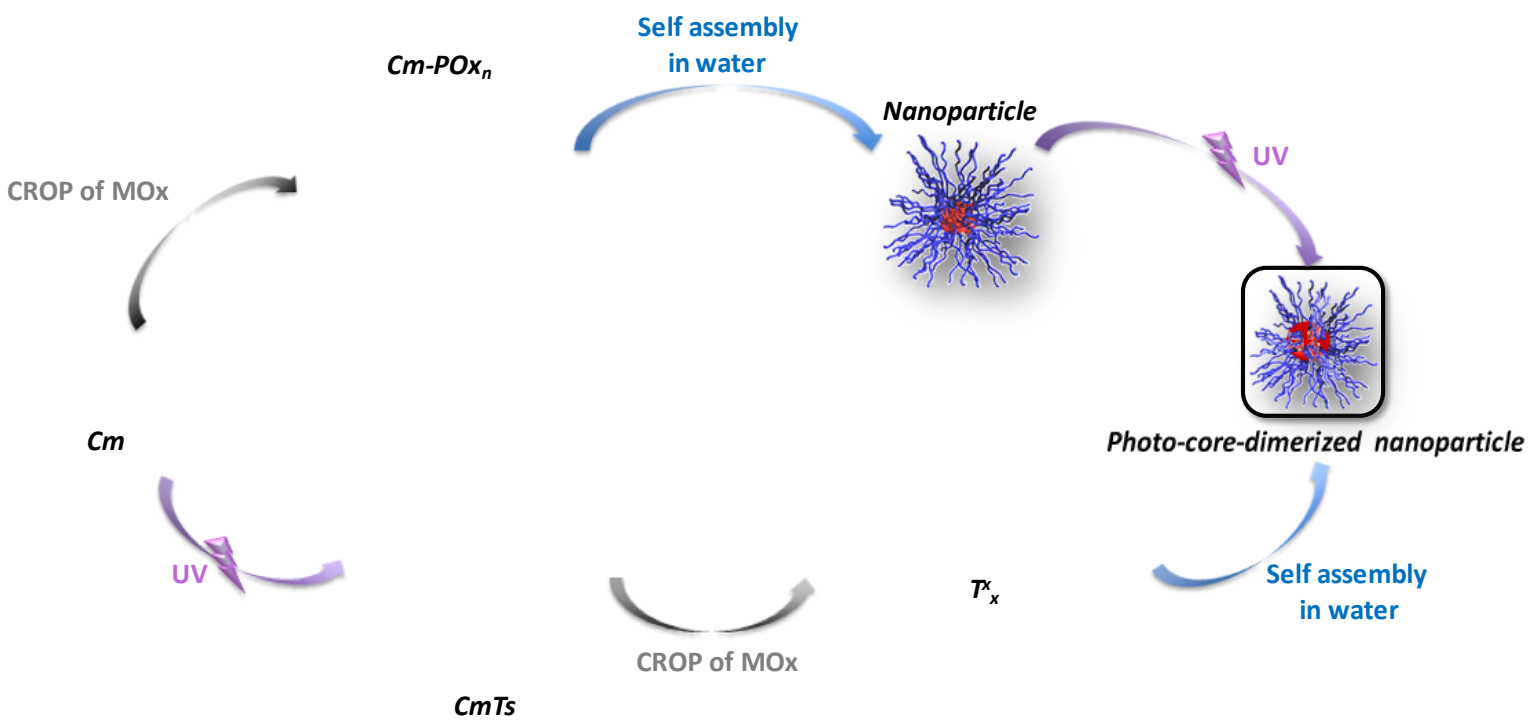

Figure 1:Triblock copolymer synthesis and the self-assembly in water relative to that of the diblock copolymer. 


\section{Results and discussion}

\section{Synthesis of the triblock copolymers $T_{x}^{x}$}

The photo-dimerization of the lipophilic UV-sensitive initiator, CmTs, into the corresponding bis-functional initiator, $\mathrm{CmTs}_{2}$, prior to the polymerization of 2-methyl-2-oxazoline was investigated (Figure 1, down route). The starting compound, CmTs, reacted both as a tosylated initiator and a photo-dimerizable system by the coumarin unit. To reach an optimal photo-conversion rate, CmTswas first dimerized into $\mathrm{CmTs}_{2}$ under $\mathrm{UV}$-illumination at $\lambda=$ $350 \mathrm{~nm}$ giving a hydrophobic bis-initiator for the cationic ring-opening polymerization (CROP) of 2-methyl-2-oxazoline (Figure 2 ). The $[2 \pi+2 \pi]$ photo-reaction was monitored by UV spectroscopy using the UV-absorbance band of the coumarin unit at $\lambda=320 \mathrm{~nm}$ (Figure SI-1). The photo-dimerization rate was confirmed by ${ }^{1} \mathrm{H}$ NMR spectroscopy regarding the shift of the characteristic signals of the unimer $\left(\mathrm{H}_{2}, \mathrm{H}_{6}, \mathrm{H}_{7}\right.$ and $\left.\mathrm{H}_{9}\right)$ into the cyclobutane dimer $\left(\mathrm{H}_{2^{*}}, \mathrm{H}_{6^{*}}, \mathrm{H}_{7^{*}}\right.$ and $\left.\mathrm{H}_{9 *}\right)($ Figure 3$)$. A maximum of dimerization rate of $88 \%$ was achieved after one hour whereas a duration of 1 or 2 days was required in the literature for another polymeric structures bearing the similar photo-active unit. ${ }^{[60,61]}$ The residual unimerCmTs was removed by recrystallization giving only $\mathrm{CmTs}_{2}$ as illustrated by comparison between CmTs and $\mathrm{CmTs}_{2}$ SEC traces (Figure SI-2).

The CROP of 2-methyl-2-oxazoline was performed under microwave conditions as regard to the low thermal stability of $\mathrm{CmTs}_{2}$. Indeed, $50 \%$ of de-dimerization was observed after severalhours at $80{ }^{\circ} \mathrm{C}$. Even though higher temperature was used $\left(140{ }^{\circ} \mathrm{C}\right)$, this technique drastically reduced the reaction time (30 min versus $15 \mathrm{~h}$ ) avoiding the scission by dedimerization of the polymer chains into amphiphilicdiblock copolymers $\left(\mathrm{Cm}-\mathrm{PO} \mathrm{x}_{\mathrm{n}}\right)$. After the termination step in the presence of potash, three photo-induced amphiphilic and symmetric 
triblock copolymers $\left(\mathrm{T}_{\mathrm{X}}^{\mathrm{X}}\right)$ were prepared knowing that the degree of polymerization of each POx block (X) ranged from 6 to 24, as reported in Table 1 .

\begin{tabular}{|c|c|c|}
\hline$\stackrel{\text { UV-irradiation }}{\longrightarrow}$ & & $\begin{array}{c}1-\mathrm{MOx}, \mathrm{CH}_{3} \mathrm{CN} \\
\text { microwaves, } 140^{\circ} \mathrm{C}\end{array}$ \\
\hline $350 \mathrm{~nm}, 1 \mathrm{~h}, \mathrm{CHCl}_{3}$ & $\mathrm{CmTs}_{2}$ & $\begin{array}{l}\text { 2-MeOH/KOH } \\
\text { RT, overnight }\end{array}$ \\
\hline
\end{tabular}

Figure 2: Synthesis of the amphiphilictriblock copolymers (e. g. $\left.\mathrm{T}_{6}^{6}\right)$.

The characteristic signals of $\mathrm{T}_{\mathrm{X}}^{\mathrm{X}}$ were detected by ${ }^{1} \mathrm{H}$ NMR spectroscopy as illustrated in Figure 3 with the occurrence of POx protons $\mathrm{H}_{\mathrm{a}}, \mathrm{H}_{\mathrm{b}}$ and $\mathrm{H}_{\mathrm{d}}$ at 2.2-1.8 and 3.7-3.2 ppm as well as the peculiar alkyl chain signals $\mathrm{H}_{11-21}$ at 4.0, 3.5, 2.25 and 1.7-1.2 ppm. The dimerization of the coumarin units were illustrated with the shift of coumarin aromatic protons $\mathrm{H}_{7} *, \mathrm{H}_{9} *$ and $\mathrm{H}_{6} *$ at6.6 and $5.9 \mathrm{ppm}$ as well as $\mathrm{H}_{2} *$ at $7.0 \mathrm{ppm}$. The very small amount of coumarin unimer showed the negligible de-dimerization during the CROP process and attest to the compatibility of this chromophore with the CROP.

Besides, by size exclusion chromatography (SEC), the monomodal traces indicated that only ABA amphiphilic copolymers were obtained without unintendedde-dimerization and formation of diblock copolymers (Figure SI-3). The relatively high dispersity of the triblock copolymers ( $Ð$ around 1.4-1.5) can be easily explained by: i) the dual functionality of the twin-initiation $\mathrm{CmTs}_{2}$, ii) the unfavourable hydrophobic character of the initiator to polymerize hydrophilic oxazoline monomer and iii) the electron-rich character of the coumarin units which could interfer during the attack of the first monomers into the coumarinated propagating chains. The low molecular weight of the resulting copolymers

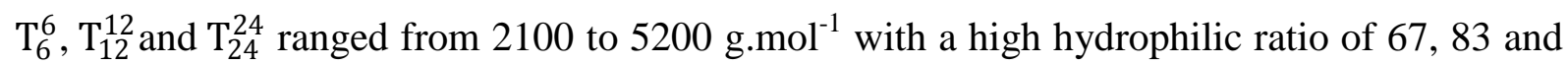


$87 \%$, respectively corresponding to $\mathrm{M}_{\text {hydrophilic }} / \mathrm{M}_{\text {hydrophobic }}$ ratioof 2, 4.9 and 6.7, respectively.

Thus, POx-based triblock copolymers bearing dimerizedcoumarin units have been successfully synthesized in a one-pot route, without traces of residual undimerized chains.

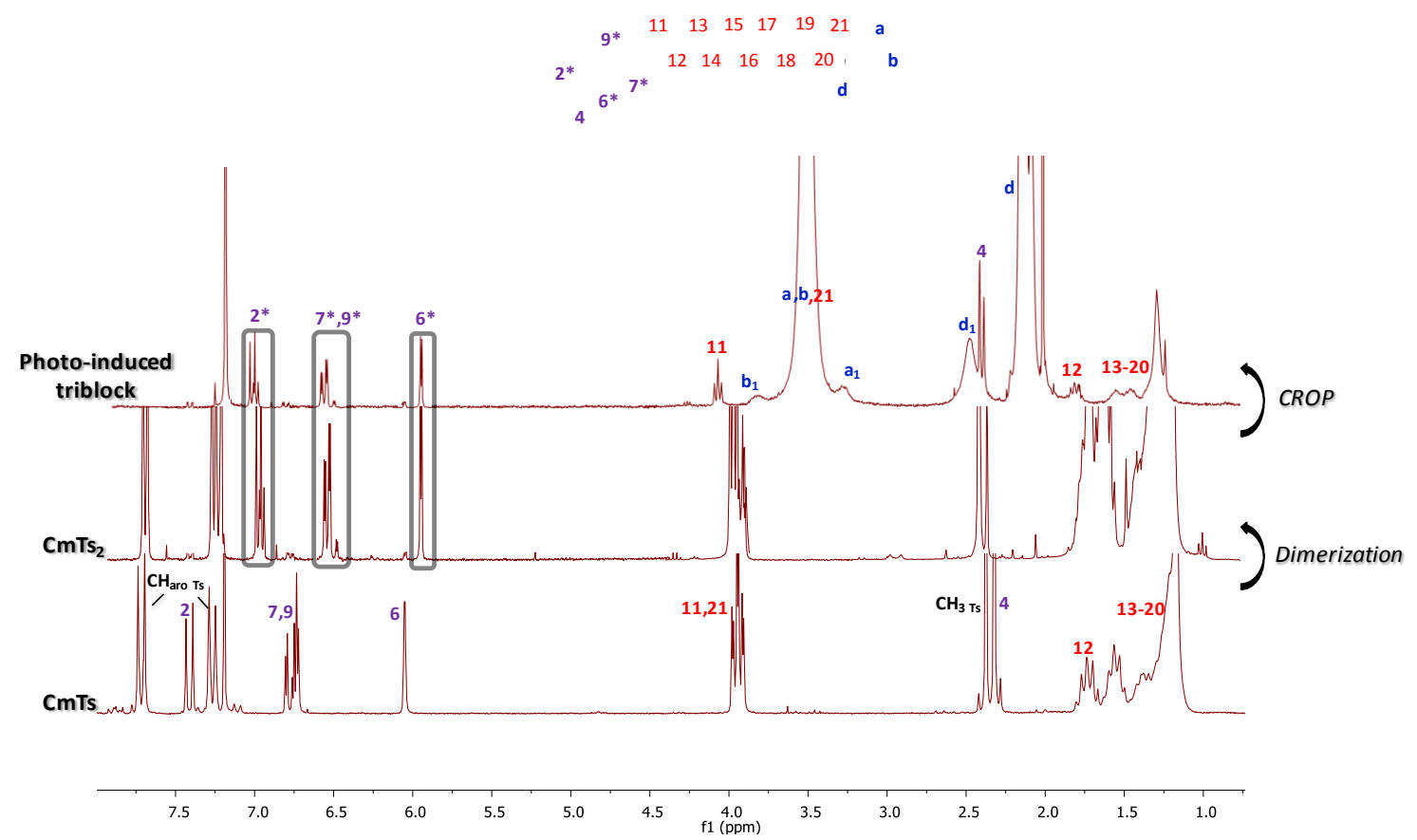

Figure $3:{ }^{1} \mathrm{H}$ NMR spectra $\left(300 \mathrm{MHz}, \mathrm{CDCl}_{3}\right)$ of CmTs, CmTs $\mathrm{S}_{2}$ and $\mathrm{T}_{6}^{6}$.

\section{Self-assembly of the photo-induced amphiphilictriblock copolymers}

The ability of the photo-induced amphiphilictriblock copolymers $\mathrm{T}_{\mathrm{X}}^{\mathrm{X}}$ to self-assemble in water into ordered nanostructures was investigated by dynamic light scattering (DLS) and transmission electron microscopy (TEM). In all cases, the nano-objects were spontaneously shaped by direct dissolution of the copolymers in aqueous media $\left(4 \mathrm{mg} \cdot \mathrm{mL}^{-1}\right)$ without any filtration. For $\mathrm{T}_{6}^{6}, \mathrm{~T}_{12}^{12}$ and $\mathrm{T}_{24}^{24}$, two distributions co-existed with a hydrodynamic diameter $\left(\mathrm{D}_{\mathrm{H}}\right)$ of around 11 and $300 \mathrm{~nm}$ as shown in Figure 4 and summarized in Table 1.They can reasonably be attributed to micellar nanoparticles and larger aggregates. We noted that the $\mathrm{D}_{\mathrm{H}}$-values of the smaller nanoparticles determined by DLS were consistent with those of 
TEM, except for $\mathrm{T}_{12}^{12}$ (nanoparticles twice larger by TEM). By DLS measurements, the length of the POx block seemed to have a little impact on the nanoparticle size and similar $\mathrm{D}_{\mathrm{H}}$-values than the corresponding photo-active diblock copolymer, $\mathrm{Cm}-\mathrm{POx}_{\mathrm{n}}$, and un-photoactive diblockcopolymer, $\mathrm{C}_{18}-\mathrm{POx}_{\mathrm{n}}$ as previously reported. ${ }^{[59]}$ Moreover, as $\mathrm{CoumC}_{11}-\mathrm{POx}_{\mathrm{n}}$, an inexplicable maximun in size was observed for the intermediate length of POx, $\mathrm{T}_{12}^{12} \cdot{ }^{[59]}$ The DLS measurements being much more sensitive to the bigger objects than smaller ones, ${ }^{[62]}$ the percentage of small nanoparticles was calculated related to the big ones according to the calculation described in the previous work on diblock copolymers. Assuming that the present nanoparticles behave like hard spheres in water and that all the nanoparticles have the same density, the percentage of small nanoparticles can be calculated using eq (1):

$$
\frac{N_{\text {Small }}}{N_{\text {Big }}}=\left(\frac{\tau_{\text {Big }}}{\tau_{\text {Small }}}\right)^{3}\left(\frac{S_{\text {Small }}}{S_{\text {Big }}}\right)
$$

where $\mathrm{N}_{\text {Small }}$ refers to the number of small nanoparticles (fast relaxation mode), $\tau_{\text {Small }}$ is the relaxation time corresponding to the small nanoparticles and $S_{\text {Small }}$ represents the surface area under the peak related to the small nanoparticles.For instance, for $\mathrm{T}_{6}^{6}$ at $90^{\circ}$, we have $\mathrm{N}_{\text {small }}=$ $1009 \mathrm{~N}_{\text {big }}$ meaning that the small nanoparticles represent $99.90 \%$ of the nanoparticles in number. The same calculation gave 99.94 and $99.76 \%$ for $\mathrm{T}_{12}^{12}$ and $\mathrm{T}_{24}^{24}$, respectively. The small amount of aggregates was confirmed on TEM images.

Table 1: Characteristics of triblock copolymers $\left(\mathrm{T}_{\mathrm{X}}^{\mathrm{X}}\right)$.

\begin{tabular}{cccccccc}
\hline Sample & $D P_{n}^{\text {POx b }}$ & $\begin{array}{c}\mathrm{M}_{\mathrm{n}, \mathrm{SEC}^{\mathrm{c}}} \\
\left(\mathrm{g} \cdot \mathrm{mol}^{-1}\right)\end{array}$ & $\bigoplus^{\mathrm{c}}$ & \multicolumn{2}{c}{$\begin{array}{c}\mathrm{D}_{\mathrm{H}}{ }^{\mathrm{d}} \\
(\mathrm{nm})\end{array}$} & $\mathrm{Ns}_{\text {mall }} / \mathrm{N}_{\mathrm{big}}{ }^{\mathrm{d}}$ & $\mathrm{D}_{\mathrm{TEM}}^{\mathrm{e}}$ \\
\hline $\mathrm{T}_{6}^{6 \mathrm{a}}$ & $6+6$ & 2100 & 1.47 & 10.6 & 353 & 1009 & 12 \\
$\mathrm{~T}_{12}^{12 \mathrm{a}}$ & $12+12$ & 4000 & 1.51 & 12.8 & 272 & 1711 & 24 \\
$\mathrm{~T}_{24}^{24 \mathrm{a}}$ & $24+24$ & 5200 & 1.44 & 9.6 & 308 & 416 & 10 \\
\hline
\end{tabular}


a: $\mathrm{CROP}$ initiated by $\mathrm{CmTs}_{2}$ performed in a microwave reactor at $140{ }^{\circ} \mathrm{C}$ in $\mathrm{CH}_{3} \mathrm{CN}$ during 30 min. ${ }^{\mathrm{b}}$ : Determined by ${ }^{1} \mathrm{H}$ NMR in $\mathrm{CDCl}_{3}{ }^{\mathrm{c}}$ : Determined by SEC in DMAc (PMMA standards). ${ }^{\mathrm{d}}$ : Determined by dynamic light scattering using CONTIN method. ${ }^{\mathrm{e}}$ : TEM image and the corresponding statistical treatment carried out on more than 300 objects.

a) $T_{6}^{6}$
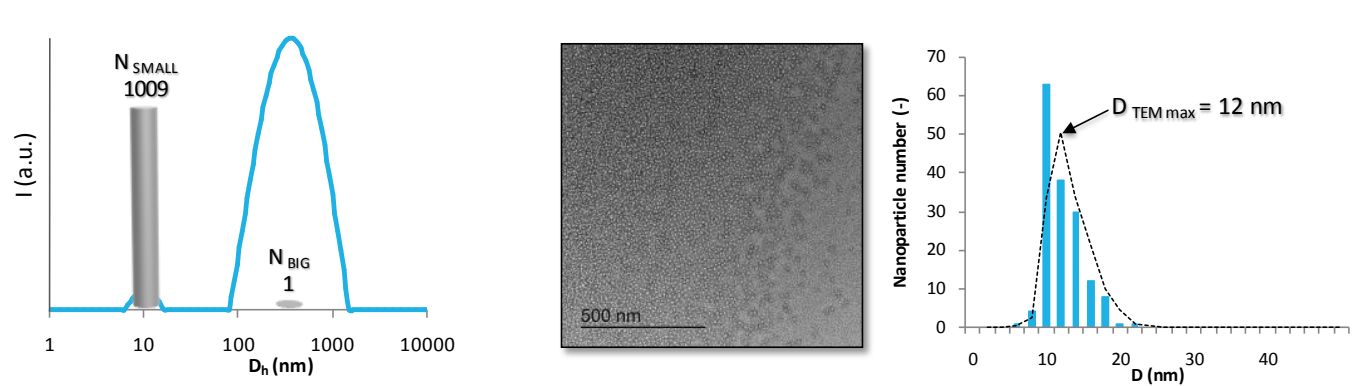

b) $\mathrm{T}_{12}^{12}$
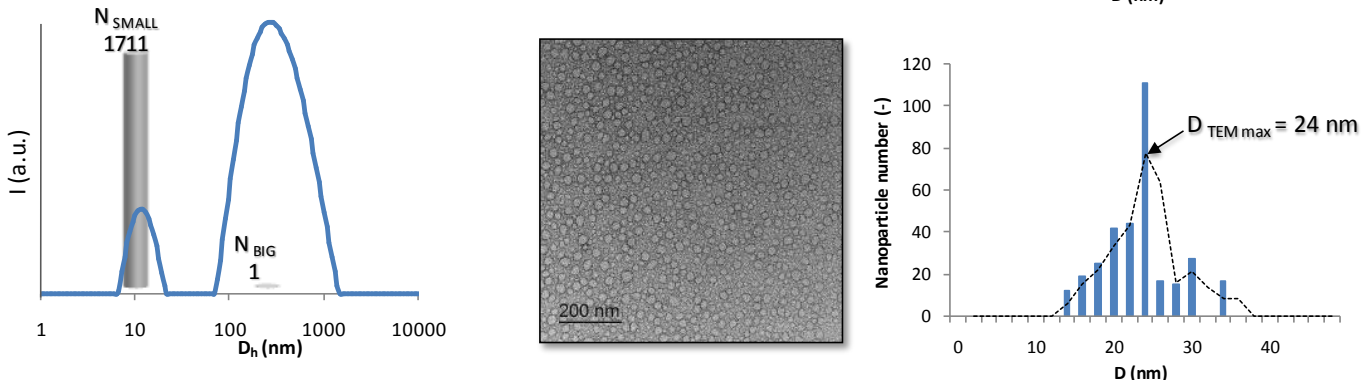

c) $\mathrm{T}_{24}^{24}$
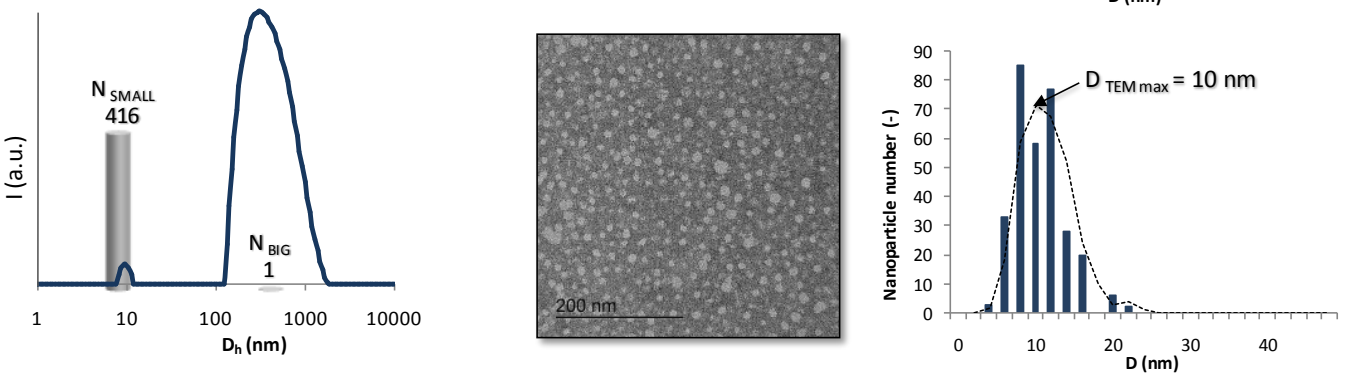

Figure 4: DLS traces and $N_{\text {small }} / N_{\text {big }}$ (bar) calculated from CONTIN analysis as well as TEM images and the corresponding statistical treatment carried out on more than 300 objects for a) $\mathrm{T}_{6}^{6}$, b) $\mathrm{T}_{12}^{12}$ and c) $\mathrm{T}_{24}^{24}$.

The efficiency of UV-illumination for the crosslinking of the nanoparticles has been proved by Zhao. ${ }^{[8]}$ This methodology is suitable fortheboth core- ${ }^{[63]}$ and shell- ${ }^{[11]}$ crosslinkedof the nanoparticles using amphiphilic grafted copolymers bearing pendent chains with UV-active species. By contrast, the photo-dimerization of the nanoparticle core employing amphiphilicdiblock copolymers has been little studied. For $\mathrm{T}_{\mathrm{x}}^{\mathrm{x}}$, the UV-dimerization of 
coumarin units occurring beforeself-assembling, the light-induced destabilization of the nanoparticles has been avoided.

A deeper observation of the TEM images of $\mathrm{T}_{X}^{X}$ revealed a non-spherical shape of the nanoparticles (Figure 5). Whatever the size, an elongated shape was observed with a diameter around 0.8-0.9 times smaller than that of the corresponding spherical nanoparticles. The original shape was illustrated with $\mathrm{T}_{12}^{12}$ giving the larger nanoparticles. Such morphology has already been described for amphiphilic copolymers containing very hydrophobic ${ }^{[64]}$ or fluorinated $^{[65]}$ blocks. Jordan et al. ${ }^{[66]}$ have also recently reported the same trend for hydrophilic/fluorophilic poly(2-oxazoline) diblock copolymers in water.

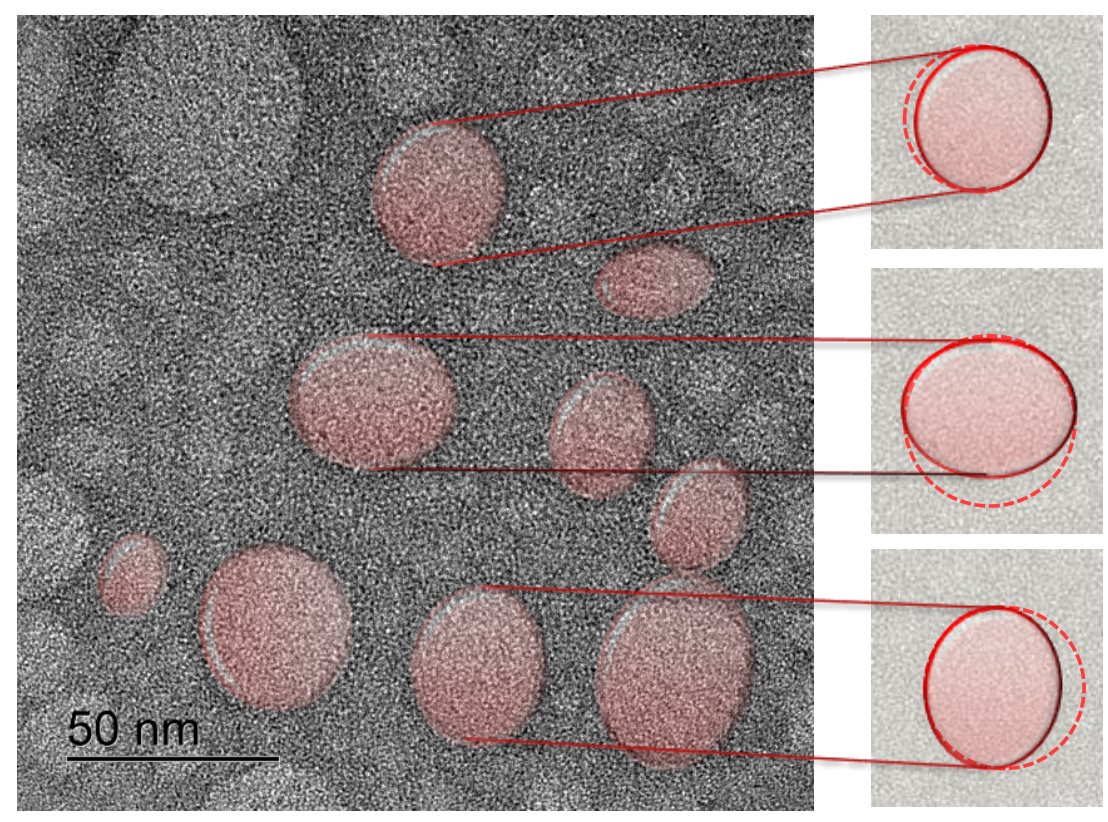

Figure 5: TEM image of non-spherical nanoparticles of $\mathrm{T}_{12}^{12}$ after direct dissolution in water (full line: contour of elongated nanoparticle and dotted line: corresponding spherical nanoparticle).

To explain this nanoparticle elongation, we proposed the crystallization of the coumarin units inducing an internal stress and a preferential orientation of the triblock copolymers. Indeed, 
the coumarin units are well-known to act as crystallization promoters by charge transfer complex and $\pi-\pi$ interactions caused by their photo-induced alignment. To check the crystallization of the nanoparticle core, a comparative DSC analysis was realized on the photo-induced triblock copolymers $\left(\mathrm{T}_{6}^{6}, \mathrm{~T}_{12}^{12}\right.$ and $\left.\mathrm{T}_{24}^{24}\right)$ and their precursor $\mathrm{CmTs}_{2}$ (Figure SI-4 and Table 2). Preliminarily to the study of the triblock copolymers, $\mathrm{CmTs}_{2}$ was investigated and shown a $\mathrm{T}_{\mathrm{g}}$-value of $-20^{\circ} \mathrm{C}$ and a $\mathrm{T}_{\mathrm{m}}$-value of $88^{\circ} \mathrm{C}$. The copolymers $\mathrm{T}_{\mathrm{x}}^{\mathrm{x}}$ crystallized with an increase of the melting temperature $\left(\mathrm{T}_{\mathrm{m}}\right)$ with the length of polyoxazoline block $\left(91{ }^{\circ} \mathrm{C}\right.$ for $\mathrm{T}_{6}^{6}$ to $135{ }^{\circ} \mathrm{C}$ for $\left.\mathrm{T}_{24}^{24}\right)$. The micro-phase segregationbetween the hydrophilic and the hydrophobic blocks was confirmed with two $\mathrm{T}_{\mathrm{g}}$-values corresponding approximatively to those of $\mathrm{CmTs}_{2}\left(\mathrm{~T}_{\mathrm{g} 1}\right)$ andpolyoxazoline $\left(\mathrm{T}_{\mathrm{g} 2}\right)$. Lastly, note that the melting enthalpy of the triblock copolymerswas higher than that of $\mathrm{CmTs}_{2}\left(-45 \mathrm{~J}^{-1}{ }^{-1}\right)$ and exceeded $-95 \mathrm{~J}_{\mathrm{g}} \mathrm{g}^{-1}$ demonstrating the higher crystalline character of $\mathrm{T}_{\mathrm{x}}^{\mathrm{x}}$.

Table 2: DSC values $\left(10^{\circ} \mathrm{C} / \mathrm{min}\right.$ under nitrogen atmosphere $)$ and XRD data of $\mathrm{CmTs}_{2}, \mathrm{~T}_{6}^{6}$, $\mathrm{T}_{12}^{12}$ and $\mathrm{T}_{24}^{24}$

\begin{tabular}{cccccc}
\hline Sample & $\mathrm{T}_{\mathrm{g} 1}$ & $\mathrm{~T}_{\mathrm{g} 2}$ & $\mathrm{~T}_{\mathrm{m}}$ & $\Delta \mathrm{H}_{\mathrm{m}}$ & $\chi_{\mathrm{c}}{ }^{\mathrm{c}}$ \\
& $\left({ }^{\circ} \mathrm{C}\right)$ & $\left({ }^{\circ} \mathrm{C}\right)$ & $\left({ }^{\circ} \mathrm{C}\right)$ & $\left(\mathrm{J}^{-g^{-1}}\right)$ & $(\%)$ \\
\hline $\mathrm{CmTs}_{2}$ & -20 & $-^{\mathrm{a}}$ & 88 & -45 & $-^{\mathrm{d}}$ \\
$\mathrm{T}_{6}^{6}$ & 5 & 53 & 91 & -95 & 26 \\
$\mathrm{~T}_{12}^{12}$ & 4 & 57 & 94 & $-{ }^{\mathrm{b}}$ & 13 \\
$\mathrm{~T}_{24}^{24}$ & -10 & 44 & 135 & -84 & 14
\end{tabular}

$\stackrel{a}{\text { a }}$ Glass transition not visible. ${ }^{\mathrm{b}}$ :None value by overlapping between the glass transition and melting phenomena. ${ }^{\mathrm{c}}$ : Determined by XRD. ${ }^{\mathrm{d}}$ : Not calculated. 
The crystalline character of $\mathrm{T}_{6}^{6}, \mathrm{~T}_{12}^{12}$ and $\mathrm{T}_{24}^{24}$ was confirmed by X-ray diffraction (XRD) analysis (Figure 6). Thanks to Bragg's law: $\mathrm{n} . \lambda=2 . \mathrm{d} \cdot \sin \theta$, where $\mathrm{n}$ represented an integer number (here, $\mathrm{n}_{\mathrm{air}}=1$ ), $\lambda$ the wavelength of the beam and $\theta$ the incident angle, each diffraction peak allowed to deduce the distance between diffracting planes, $d(\AA)$. In addition, to a broad diffusion peak between 4 and $6 \AA$, a high sharp peak was detected at $3.2 \AA$ for each $\mathrm{T}_{\mathrm{x}}^{\mathrm{x}}$. Additional peaks at 5.7, 5.1, 4.5, 4.1 and $3.5 \AA$, characteristic to long distance interactions and spaced with the same gap $(0.6 \AA)$, were observed for the triblock with shorter POx chains $\left(\mathrm{T}_{6}^{6}\right)$ that demonstrated its higher ability to crystallize.XRD and DSC analyses were in good agreement and gave the same evolution of thecrystallinitywith the length of POx block. Besides, the crystallization phenomenon was lower for $\mathrm{T}_{24}^{24}$ than for $\mathrm{T}_{6}^{6}$ since only the high sharp peak at $3.2 \AA$ was observed. The crystallization was disturbed by the longer POx chains as evidenced by the measurement of the crystallinity ratio $\left(\chi_{c}\right)$ ranging from 13 to $26 \%$ (Table 2). The crystallinity ratio was calculated through the crystalline area $\left(\mathrm{A}_{\mathrm{a}}\right)$ and the amorphous area $\left(\mathrm{A}_{\mathrm{c}}\right)$ obtained by $\mathrm{DRX} \mathrm{X}^{[67-69]}$ according to equation 2:

$$
\chi_{c=\frac{A_{c}}{A_{a}+A_{c}}}
$$

Furthermore, the DSC thermograms also confirmed this tendency since the highest melting temperature $\left(\mathrm{T}_{\mathrm{m}}=135^{\circ} \mathrm{C}\right)$ was measured for the longest triblock copolymer $\mathrm{T}_{24}^{24}$.

Thus, the architecture of the POx-based amphiphilic copolymers bearing coumarin units has a real impact on their physico-chemical properties. The photo-dimerization of coumarin groups before self-assembly favoured the crystallization and further the segregation between hydrophobic and hydrophilic blocks of $\mathrm{T}_{\mathrm{x}}^{\mathrm{x}}$. Thecrystallization of the coumarin dimers and a part of the neighbouring POx chains seemedto occur according to a preferential direction producing non-spherical nanoparticles by $\pi$-stacking interactions between aromatic rings of coumarin dimers. 


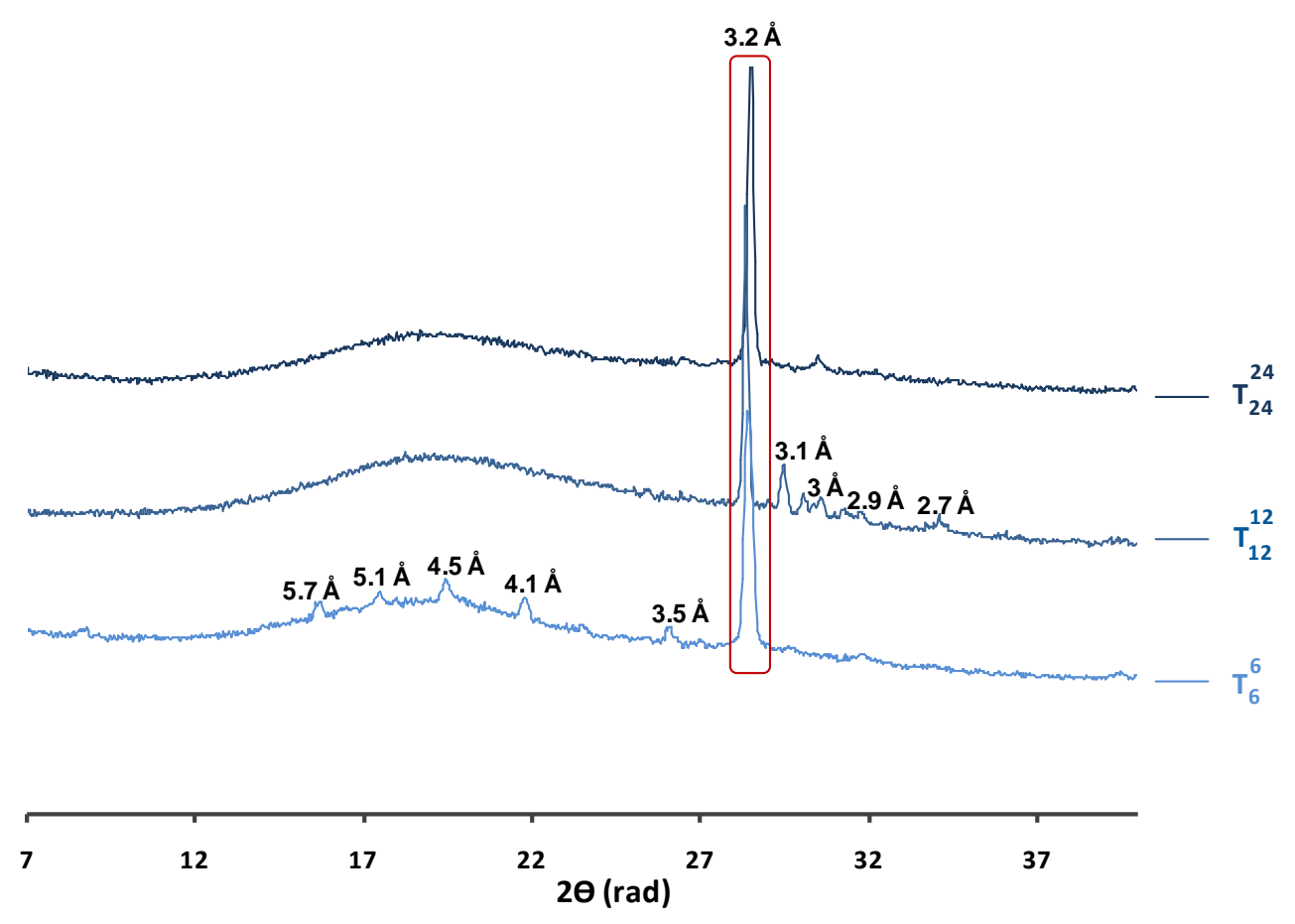

Figure 6: X-ray diffraction patterns measured by powder method for $\mathrm{T}_{6}^{6}, \mathrm{~T}_{12}^{12}$ and $\mathrm{T}_{24}^{24}$. 


\section{Experimental}

\section{Materials}

2-Methyl-2-oxazoline (MOx) was dried and distilled from $\mathrm{CaH}_{2}$ and stored under dry nitrogen atmosphere. CmTs was synthesized according to a procedure previously described. ${ }^{[59]}$ Anhydrous acetonitrile, diethylether, ethanol, methanol, $\mathrm{MgSO}_{4}$ and potash $(\mathrm{KOH})$ were commercial products (Sigma Aldrich) and used without further purification.

\section{Measurements}

The UV-dimerization of the CmTs was performed in a cylindrical photochemical reactor “RayonnetRPR-200” equipped with 16 symmetrically placed lamps with emission in $350 \mathrm{~nm}$ (UV-B). The samples were irradiated in quartz flasks placed on a circular rotating holder.The polymerization reactions were performed in capped reaction vials specially designed for the single-mode microwave. The microwave reactor system used was a Monowave 300 from Anton-Paar. These hot vials, allowed to cool to room temperature, and filled with argon prior to use. All experiments were performed on $30 \mathrm{~mL}$ solutions; the polymerization reactions were terminated by adding methanolic potash to the reaction mixture at room temperature outside the microwave system.Nuclear magnetic resonance (NMR) spectra were recorded on a NMR BrukerAvance I $300 \mathrm{MHz}$ or on a BrukerAvance III $600 \mathrm{MHz}$ spectrometers. The chemical shifts were in part per million (ppm) where (s) means a singlet, (d) a doublet, (t) a triplet, (m) a multiplet and (dd) a doublet of doublet. Chemical shifts ( ${ }^{1} \mathrm{H}$ NMR) were referenced to the peak of residual $\mathrm{CHCl}_{3}$ at $7.26 \mathrm{ppm}$. Size exclusion chromatography (SEC) with $\mathrm{N}, \mathrm{N}$-dimethylacetamide (DMAc) (with $0.1 \mathrm{w} / \mathrm{w} \% \mathrm{LiCl}$ ) as eluent at a flow rate of 0.8 $\mathrm{mL} \min ^{-1}$, calibrated with poly(methylmethacrylate) (PMMA) standards, was performed on a PL-GPC 50 Plus equipped with a Varian model 410 autosampler. The SEC apparatus 
comprised a refractive index detector and was filled with a $8 \mu \mathrm{m}$ PolarGel-M pre-column (7.5 $\times 50 \mathrm{~mm})$ and two $8 \mu \mathrm{m}$ PolarGel-M columns $(7.5 \times 300 \mathrm{~mm})$ thermostated at $50^{\circ} \mathrm{C}$.Dynamic light scattering (DLS) measurements were performed using an ALV/CGS-8FS/N069 apparatus (from ALV) equipped with an ALV/LSE-5004 multiple $\tau$ digital correlator with a $125 \mathrm{~ns}$ initial sampling time (from ALV) and a $35 \mathrm{~mW}$ red He-Ne linearly polarized laser operating at a wavelength of $632.8 \mathrm{~nm}$ (from JDSU). The copolymer suspensions in water were obtained by direct copolymer dissolution in Milli-Q water (characterized by a resistivity of $18.2 \mathrm{M} \Omega . \mathrm{cm}$ ) at a concentration of $4 \mathrm{mg} \cdot \mathrm{mL}^{-1}$ without filtration,loaded in $10 \mathrm{~mm}$ diameter cylindrical cells and then maintained at a constant temperature of $25.0 \pm 0.1{ }^{\circ} \mathrm{C}$ prior to measurement. In DLS, the relaxation time distribution was obtained using CONTIN analysis of the autocorrelation function $\left(\mathrm{g}^{(2)}-1\right)$.Sample preparation for TEM analysis was done as follows: $10 \mu \mathrm{L}$ of aqueous copolymer suspensions concentrated at $0.04 \mathrm{mg} \cdot \mathrm{mL}^{-1}$ were dropped onto glow discharged carbon-coated copper grids (Agar scientific, $\mathrm{Cu}-300)$ and the excess liquid was blotted thanks to filter paper. Then, $10 \mu \mathrm{L}$ of a $4 \mathrm{w} / \mathrm{v} \%$ aqueous uranyl acetate negative stain solution was added. After 30 seconds, the excess of liquid was again blotted. TEM imaging was performed using a JEOL, JEM - 2200FS microscope operating at $200 \mathrm{kV}$.Statistical treatment of the images carried out on more than 300 objects gives the main diameter.Calorimetric analyses were carried out at $10^{\circ} \mathrm{C} / \mathrm{min}$ under nitrogen atmosphere using a Star1 differential scanning calorimeter (DSC) from Mettler Toledo.X-ray diffraction (XRD) analysis were performed on a X-pert powder diffractometer with a $10 \mathrm{~mm}$ mask, a divergent fente of $1 / 4^{\circ}$ on silicium surface to avoid noise signal. UV-visible analyses were conducted with a Perkin Elmer - lambda 35 UV/Vis spectrometer equipped with PTP-1+1 Peltier System in vial quartz $(\mathrm{l}=1 \mathrm{~cm})$. 


\section{Dimerized initiator: $\mathrm{CmTs}_{2}$}

In a quartz closed flask, a solution of the initiator CmTs (10 g, $20 \mathrm{mmol})$ in chloroform (30 $\mathrm{mL}$ ) was exposed to UV irradiation at $\lambda=350 \mathrm{~nm}$ (UV-B) for one hour in cylindrical photochemical reactor. The dimer was separated to the corresponding unimer by recrystallization from ethanol (four times). The white powder corresponding to the unimer was removed giving $\mathrm{CmTs}_{2}$ in a $72 \%$ yield.

${ }^{1} \mathrm{H}$ NMR $\left(300 \mathrm{MHz}, \mathrm{CDCl}_{3}\right), \delta(\mathrm{ppm}): 7.8\left(\mathrm{~d}, 4 \mathrm{H}, \mathrm{CH}_{\text {aroTs }}\right), 7.3\left(\mathrm{~d}, 4 \mathrm{H}, \mathrm{CH}_{\text {aroTs }}\right), 7.0(\mathrm{~d}, 2 \mathrm{H}$, $\left.\mathrm{H}_{2^{*}}\right), 6.6\left(\mathrm{~m}, 4 \mathrm{H}, \mathrm{H}_{7^{*}}\right.$ and $\left.\mathrm{H}_{9 *}\right), 5.8\left(\mathrm{~s}, 2 \mathrm{H}, \mathrm{H}_{6^{*}}\right), 3.9\left(\mathrm{~m}, 4 \mathrm{H}, \mathrm{CH}_{2}-\mathrm{O}-\right), 3.5\left(\mathrm{~m}, 8 \mathrm{H}, \mathrm{H}_{11}\right.$ and $\left.\mathrm{H}_{21}\right), 2.4\left(\mathrm{~s}, 6 \mathrm{H}, \mathrm{CH}_{3 \mathrm{Ts}}\right), 2.3\left(\mathrm{~s}, 6 \mathrm{H}, \mathrm{H}_{4}\right), 1.8\left(\mathrm{~m}, 4 \mathrm{H}, \mathrm{H}_{12}\right), 1.5-1.2\left(\mathrm{~m}, 32 \mathrm{H}, \mathrm{H}_{13}-\mathrm{H}_{20}\right) \cdot \mathrm{m}_{\mathrm{p}}=$ $80^{\circ} \mathrm{C}$

\section{Linear triblock copolymers: $\mathrm{T}_{\mathrm{x}}^{\mathrm{x}}$}

A typical procedure for the synthesis of $\mathrm{T}_{12}^{12}$ with a targeted molecularweight of 4000 g.mol ${ }^{-1}$ was described here. The dimerized initiator $\mathrm{CmTs}_{2}(2.44 \mathrm{~g}, 3 \mathrm{mmol})$ and $\mathrm{MOx}(10 \mathrm{~g}, 118$ mmol) were dissolved in $30 \mathrm{~mL}$ of dry acetonitrile in a quartz closed vial. The solution was vigorously stirred under microwave conditions at $140{ }^{\circ} \mathrm{C}$ for $30 \mathrm{~min}$ at constant pressure. The polymerization was terminated by addition of an adequate amount of methanolic potassium hydroxide $(0.7 \mathrm{~g}, 13 \mathrm{mmol}, 5 \mathrm{M})$. The flask was maintained at $30{ }^{\circ} \mathrm{C}$ for $4 \mathrm{~h}$. After cooling, the polymer was isolated by slow precipitation into cold diethylether and dried under vacuum overnight.

${ }^{1} \mathrm{H}$ NMR (300 MHz, $\left.\mathrm{CDCl}_{3}\right), \delta(\mathrm{ppm}): 7.0\left(\mathrm{~d}, 2 \mathrm{H}, \mathrm{H}_{2 *}\right), 6.6\left(\mathrm{dxd}, 4 \mathrm{H}, \mathrm{H}_{7 *}\right.$ andH $\left.\mathrm{H}^{*}\right), 5.9(\mathrm{~s}, 2 \mathrm{H}$, $\left.\mathrm{H}_{6^{*}}\right), 4\left(\mathrm{t}, 4 \mathrm{H}, \mathrm{H}_{11}\right), 3.7-3.2\left(\mathrm{~m}, 8 \mathrm{nH}, \mathrm{H}_{\mathrm{a}}\right.$ and $\left.\mathrm{H}_{\mathrm{b}}\right), 3.5\left(\mathrm{~m}, 4 \mathrm{H}, \mathrm{H}_{21}\right), 2.5\left(\mathrm{~s}, 6 \mathrm{H}, \mathrm{H}_{\mathrm{d} 1}\right), 2.25(\mathrm{~s}$, $\left.6 \mathrm{H}, \mathrm{H}_{4}\right), 2.2-1.8\left(\mathrm{~m}, 6 \mathrm{nH}, \mathrm{H}_{\mathrm{d}}\right), 1.75-1.2\left(\mathrm{~m}, 36 \mathrm{H}, \mathrm{H}_{12}-\mathrm{H}_{20}\right)$. 


\section{Conclusion}

This study demonstrates the potential interest of the photo-dimerization of amphiphilic linear copolymers related to the photo-crosslinking of nanoparticle core using amphiphilic grafted copolymers. Otherwise, the benefits of the self-assembly of amphiphilictriblock copolymers, previously prepared by photo-dimerization can be summarized as follows: i) high photoconversion of coumarins without any unfavourable de-dimerization and retro-formation of diblock copolymers during the CROP process, ii) few aggregationsof nanoparticles showing a sharp segregation phase between hydrophilic and hydrophobic blocks, and iii) original morphology of nanoparticles with non-spherical shape that can be attributed to the crystallization of the coumarin moieties until 26\%. More studies are underway in our laboratory to demonstrate the difference in term of stability, loading and release of active molecules between different nano-objects based on polyoxazoline and coumarin (photodimerized spherical nanoparticles using the diblock route, photo-dimerizedovalic nanoparticles using the triblock route and photo-crosslinked spherical nanoparticles using grafted copolymers).

\section{Acknowledgements}

The authorsthank the "Ministère de l'Enseignement Supérieur et de la Recherche" and the "Centre National de la Recherche Scientifique" for financial support. They are thankful to Dr. ErwanOliviero from ICGM technical plateform for TEM imaging, to Dr. Joel Couve for DSC measurements and Dr. Bernard Fraisse for XRD analysis. They also thank Dr.RedouaneBorsali and Dr. Christophe Traveletfrom CERMAV for DLS experiments. 


\section{References}

[1] C. Giacomelli, V. Schmidt, K. Aissou, R. Borsali; Block Copolymer Systems: From Single Chain to Self-Assembled Nanostructures, Langmuir, 26 (2010) 15734-15744.

[2] Y. Mai,A. Eisenberg; Self-assembly of block copolymers, Chemical Society Reviews, 41 (2012) 5969-5985.

[3] T. P. Lodge; Block Copolymers: Past Successes and Future Challenges, Macromolecular Chemistry and Physics, 204 (2003) 265-273.

[4] C. Bouilhac, E. Cloutet, D. Taton, A. Deffieux, R. Borsali, H. Cramail; Block copolymer micelles as nanoreactors for single-site polymerization catalysts, Journal of Polymer Science Part A: Polymer Chemistry, 47 (2009) 197-209.

[5] C. Travelet, C. Bouilhac, J.-J. Robin, R. Borsali; Self-assembly of phosphorous containing oligomers: morphological features and $\mathrm{pH}$-sensitiveness in suspension, Soft Matter, 10 (2014) 7545-7557.

[6] G. Lopez, M. Guerre, J. Schmidt, Y. Talmon, V. Ladmiral, J.-P. Habas, B. Ameduri; An amphiphilic PEG-b-PFPE-b-PEG triblock copolymer: synthesis by CuAAC click chemistry and self-assembly in water, Polymer Chemistry, 7 (2016) 402-409.

[7] C. De Las Heras Alarcon, S. Pennadam, C. Alexander; Stimuli responsive polymers for biomedical applications, Chemical Society Reviews, 34 (2005) 276-85.

[8] J. Jiang, B. Qi, M. Lepage, Y. Zhao; Polymer Micelles Stabilization on Demand through Reversible Photo-Cross-Linking, Macromolecules, 40 (2007) 790-792.

[9] J. Tao,G. Liu; Polystyrene-block-poly(2-cinnamoylethyl methacrylate) Tadpole Molecules, Macromolecules, 30 (1997) 2408-2411.

[10] J. Zhang, X. Jiang, Y. Zhang, Y. Li, S. Liu; Facile Fabrication of Reversible Core Cross-Linked Micelles Possessing Thermosensitive Swellability, Macromolecules, 40 (2007) 9125-9132.

[11] E. S. Read,S. P. Armes; Recent advances in shell cross-linked micelles, Chemical Communications, (2007) 3021-3035.

[12] S. Fujii, Y. Cai, J. V. M. Weaver, S. P. Armes; Syntheses of Shell Cross-Linked Micelles Using Acidic ABC Triblock Copolymers and Their Application as $\mathrm{pH}-$ Responsive Particulate Emulsifiers, Journal of the American Chemical Society, 127 (2005) 7304-7305. 
[13] X. Jiang, S. Luo, S. P. Armes, W. Shi, S. Liu; UV Irradiation-Induced Shell CrossLinked Micelles with pH-Responsive Cores Using ABC Triblock Copolymers, Macromolecules, 39 (2006) 5987-5994.

[14] A. Guo, G. Liu, J. Tao; Star Polymers and Nanospheres from Cross-Linkable Diblock Copolymers, Macromolecules, 29 (1996) 2487-2493.

[15] F. Henselwood,G. Liu; Water-Soluble Nanospheres of Poly(2-cinnamoylethyl methacrylate)-block-poly(acrylic acid), Macromolecules, 30 (1997) 488-493.

[16] J. Ding,G. Liu; Hairy, Semi-shaved, and Fully Shaved Hollow Nanospheres from Polyisoprene-block-poly(2-cinnamoylethyl methacrylate), Chemistry of Materials, 10 (1998) 537-542.

[17] J. Tao, S. Stewart, G. Liu, M. Yang; Star and Cylindrical Micelles of Polystyreneblock-poly(2-cinnamoylethyl methacrylate) in Cyclopentane, Macromolecules, 30 (1997) 2738-2745.

[18] V. Bütün, N. C. Billingham, S. P. Armes; Synthesis of Shell Cross-Linked Micelles with Tunable Hydrophilic/Hydrophobic Cores, Journal of the American Chemical Society, 120 (1998) 12135-12136.

[19] X. Jiang, G. Zhang, R. Narain, S. Liu; Covalently stabilized temperature and pH responsive four-layer nanoparticles fabricated from surface 'clickable' shell crosslinked micelles, Soft Matter, 5 (2009) 1530-1538.

[20] S. Mavila, O. Eivgi, I. Berkovich, N. G. Lemcoff; Intramolecular Cross-Linking Methodologies for the Synthesis of Polymer Nanoparticles, Chemical Reviews, 116 (2016) 878-961.

[21] Y. Chen, A. E. Tavakley, T. M. Mathiason, T. A. Taton; Photocrosslinked poly(vinylbenzophenone)-core micelles via mild Friedel-Crafts benzoylation of polystyrene amphiphiles, Journal of Polymer Science Part A: Polymer Chemistry, 44 (2006) 2604-2614.

[22] G. Kaur, P. Johnston, K. Saito; Photo-reversible dimerisation reactions and their applications in polymeric systems, Polymer Chemistry, 5 (2014) 2171-2186.

[23] S. Chatani, C. J. Kloxin, C. N. Bowman; The power of light in polymer science: photochemical processes to manipulate polymer formation, structure, and properties, Polymer Chemistry, 5 (2014) 2187-2201.

[24] J. Babin, M. Lepage, Y. Zhao; "Decoration" of Shell Cross-Linked Reverse Polymer Micelles Using ATRP: A New Route to Stimuli-Responsive Nanoparticles, Macromolecules, 41 (2008) 1246-1253. 
[25] Y. Huang, R. Dong, X. Zhu, D. Yan; Photo-responsive polymeric micelles, Soft Matter, 10 (2014) 6121-6138.

[26] J. S. Kim,J. H. Youk; Preparation of core cross-linked micelles using a photo-crosslinking agent, Polymer, 50 (2009) 2204-2208.

[27] Q. G. Ma, E. E. Remsen, T. Kowalewski, K. L. Wooley; J. Am. Chem. Soc., 123 (2001) 4627.

[28] J. He, X. Tong, Y. Zhao; Photoresponsive Nanogels Based on Photocontrollable Cross-Links, Macromolecules, 42 (2009) 4845-4852.

[29] S.-I. Yusa, M. Sugahara, T. Endo, Y. Morishima; Preparation and Characterization of a pH-Responsive Nanogel Based on a Photo-Cross-Linked Micelle Formed From Block Copolymers with Controlled Structure, Langmuir, 25 (2009) 5258-5265.

[30] J. Tao, G. Liu, J. Ding, M. Yang; Cross-Linked Nanospheres of Poly(2cinnamoylethyl methacrylate) with Immediately Attached Surface Functional Groups, Macromolecules, 30 (1997) 4084-4089.

[31] W. J. Schreier, T. E. Schrader, F. O. Koller, P. Gilch, C. E. Crespo-Hernández, V. N. Swaminathanet, B. Kohler; Thymine Dimerization in DNA Is an Ultrafast Photoreaction, Science, 315 (2007) 625-629.

[32] D. Wang,X. Wang; Amphiphilic azo polymers: Molecular engineering, self-assembly and photoresponsive properties, Progress in Polymer Science, 38 (2013) 271-301.

[33] Y. Shi, R. M. Cardoso, C. F. Van Nostrum, W. E. Hennink; Anthracene functionalized thermosensitive and UV-crosslinkable polymeric micelles, Polym. Chem., 6 (2015) 2048-2053.

[34] S. R. Trenor, A. R. Shultz, B. J. Love, T. E. Long; Coumarins in Polymers: From Light Harvesting to Photo-Cross-Linkable Tissue Scaffolds, Chemical Reviews, 104 (2004) 3059-3078.

[35] S. Dahmane, A. Lasia, Y. Zhao; Electrochemically Active Block Copolymer Micelles Containing Coumarin Moieties, Macromolecular Chemistry and Physics, 209 (2008) 1065-1072.

[36] T. Wolff,H. Gorner; Photodimerization of coumarin revisited: Effects of solvent polarity on the triplet reactivity and product pattern, Physical Chemistry Chemical Physics, 6 (2004) 368-376.

[37] J.-O. Joswig, T. Lorenz, G. Seifert; Photoexcitation in Dimers of Coumarin and 6Alkylcoumarins, Zeitschrift für Physikalische Chemie, 228 (2014) 
[38] K. Iliopoulos, O. Krupka, D. Gindre, M. Sallé; Reversible Two-Photon Optical Data Storage in Coumarin-Based Copolymers, Journal of the American Chemical Society, 132 (2010) 14343-14345.

[39] J. He,Y. Zhao; Light-responsive polymer micelles, nano- and microgels based on the reversible photodimerization of coumarin, Dyes and Pigments, 89 (2011) 278-283.

[40] J. He, L. Tremblay, S. Lacelle, Y. Zhao; Preparation of polymer single chain nanoparticles using intramolecular photodimerization of coumarin, Soft Matter, 7 (2011) 2380-2386.

[41] G. Xu, C. Shi, D. Guo, L. Wang, Y. Ling, X. Han, J. Luo; Functional-segregated coumarin-containing telodendrimer nanocarriers for efficient delivery of SN-38 for colon cancer treatment, Acta Biomaterialia, 21 (2015) 85-98.

[42] Q. Jin, X. Liu, G. Liu, J. Ji; Fabrication of core or shell reversibly photo cross-linked micelles and nanogels from double responsive water-soluble block copolymers, Polymer, 51 (2010) 1311-1319.

[43] R. Hoogenboom,H. Schlaad; Bioinspired Poly(2-oxazoline)s, Polymers, 3 (2011) 467.

[44] R. Hoogenboom; Poly(2-oxazoline)s: A Polymer Class with Numerous Potential Applications, Angewandte Chemie International Edition, 48 (2009) 7978-7994.

[45] D. Rayeroux, V. Lapinte, P. Lacroix-Desmazes; One-pot synthesis of amphiphilic diblock copolymers of poly(styrene) and poly(2-methyl-2-oxazoline) by the direct combination of reverse iodine transfer polymerization (RITP) and cationic ringopening polymerization (CROP) processes, Journal of Polymer Science Part A: Polymer Chemistry, 50 (2012) 4589-4593.

[46] B. Guillerm, S. Monge, V. Lapinte, J.-J. Robin; Well-defined poly(oxazoline)-bpoly(acrylate) amphiphilic copolymers: From synthesis by polymer-polymer coupling to self-organization in water, Journal of Polymer Science Part A: Polymer Chemistry, 51 (2013) 1118-1128.

[47] C. Alexis, C. Charnay, V. Lapinte, J.-J. Robin; Hydrophilization by coating of silylated polyoxazoline using sol-gel process, Progress in Organic Coatings, 76 (2013) 519-524.

[48] B. Guillerm, S. Monge, V. Lapinte, J.-J. Robin; Novel Investigations on Kinetics and Polymerization Mechanism of Oxazolines Initiated by Iodine, Macromolecules, 43 (2010) 5964-5970. 
[49] B. Guillerm, S. Monge, V. Lapinte, J.-J. Robin; How to Modulate the Chemical Structure of Polyoxazolines by Appropriate Functionalization, Macromolecular Rapid Communications, 33 (2012) 1600-1612.

[50] C. Giardi, V. Lapinte, Charnay, C.; Robin, J. J.; Nonionic polyoxazoline surfactants based on renewable source: Synthesis, surface and bulk properties, React. Funct. Polym., 69 (2009) 643-649.

[51] C. Giardi, V. Lapinte, F. Nielloud, J.-M. Devoisselle, J.-J. Robin; Synthesis of polyoxazolines using glycerol carbonate derivative and end chains functionalization via carbonate and isocyanate routes, Journal of Polymer Science Part A: Polymer Chemistry, 48 (2010) 4027-4035.

[52] C. Travelet, M. Stemmelen, V. Lapinte, F. Dubreuil, J.-J. Robin, R. Borsali; Amphiphilic copolymers based on polyoxazoline and grape seed vegetable oil derivatives: self-assemblies and dynamic light scattering, Journal of Nanoparticle Research, 15 (2013)

[53] M. Stemmelen, C. Travelet, V. Lapinte, R. Borsali, J.-J. Robin; Synthesis and selfassembly of amphiphilic polymers based on polyoxazoline and vegetable oil derivatives, Polymer Chemistry, 4 (2013) 1445-1458.

[54] R. Hoogenboom, M. W. M. Fijten, G. Kickelbick, U. S. Schubert; Synthesis and crystal structures of multifunctional tosylates as basis for star-shaped poly(2-ethyl-2oxazoline)s, Beilstein Journal of Organic Chemistry, 6 (2010) 773-783.

[55] M. P. Kurlykin, A. E. Bursian, M. M. Dudkina, A. V. Ten'kovtsev; Synthesis of StarShaped Polymers Based on 2-ALKYL-2-Oxazoline with a Calix[8]Arene Central Core and the Study of Their Heat-Sensitive Properties, Fibre Chemistry, 47 (2015) 291-297.

[56] U. S. Schubert,M. Heller; Metallo-Supramolecular Initiators for the Preparation of Novel Functional Architectures, Chemistry - A European Journal, 7 (2001) 52525259 .

[57] S. Kobayashi, H. Uyama, Y. Narita, J. Ishiyama; Novel multifunctional initiators for polymerization of 2-oxazolines, Macromolecules, 25 (1992) 3232-3236.

[58] V. V. Jerca, F. A. Nicolescu, D. S. Vasilescu, D. M. Vuluga; Synthesis of a new oxazoline macromonomer for dispersion polymerization, Polymer Bulletin, 66 (2011) 785-796.

[59] L. Korchia, C. Bouilhac, V. Lapinte, C. Travelet, R. Borsali, J.-J. Robin; Photodimerization as an alternative to photocrosslinking of nanoparticles: proof of 
concept with amphiphilic linear polyoxazoline bearing coumarin unit, Polymer Chemistry, 6 (2015) 6029-6039.

[60] Z. S. Kean, G. R. Gossweiler, T. B. Kouznetsova, G. B. Hewage, S. L. Craig; A coumarin dimer probe of mechanochemical scission efficiency in the sonochemical activation of chain-centered mechanophore polymers, Chemical Communications, 51 (2015) 9157-9160.

[61] H. Suzuki, T. Tamura; Process for production of coumarin dimer compound, US Pat., US 8,258 (2012)

[62] K. Loos, A. Böker, H. Zettl, M. Zhang, G. Krausch, A. H. E. Müller; Micellar Aggregates of Amylose-block-polystyrene Rod-Coil Block Copolymers in Water and THF, Macromolecules, 38 (2005) 873-879.

[63] Y. Zhao; Light-Responsive Block Copolymer Micelles, Macromolecules, 45 (2012) 3647-3657.

[64] J. Q. Zhao, E. M. Pearce, T. K. Kwei, H. S. Jeon, P. K. Kesani, N. P. Balsara; Micelles Formed by a Model Hydrogen-Bonding Block Copolymer, Macromolecules, 28 (1995) 1972-1978.

[65] W. F. Edmonds, Z. Li, M. A. Hillmyer, T. P. Lodge; Disk Micelles from Nonionic Coil-Coil Diblock Copolymers, Macromolecules, 39 (2006) 4526-4530.

[66] R. Ivanova, T. Komenda, T. B. Bonné, K. Lüdtke, K. Mortensen, P. K. Pranzaset al.C. M. Papadakis; Micellar Structures of Hydrophilic/Lipophilic and Hydrophilic/Fluorophilic Poly(2-oxazoline) Diblock Copolymers in Water, Macromolecular Chemistry and Physics, 209 (2008) 2248-2258.

[67] A. L. Demirel, P. Tatar Güner, B. Verbraeken, H. Schlaad, U. S. Schubert, R. Hoogenboom; Revisiting the crystallization of poly(2-alkyl-2-oxazoline)s, Journal of Polymer Science Part B: Polymer Physics, 54 (2016) 721-729.

[68] A. L. Demirel, M. Meyer, H. Schlaad; Formation of Polyamide Nanofibers by Directional Crystallization in Aqueous Solution, Angewandte Chemie International Edition, 46 (2007) 8622-8624.

[69] V. V. Jerca, K. Lava, B. Verbraeken, R. Hoogenboom; Poly(2-cycloalkyl-2oxazoline)s: high melting temperature polymers solely based on Debye and Keesom van der Waals interactions, Polymer Chemistry, 7 (2016) 1309-1322. 